\title{
Design of an Optimal off-grid Hybrid Energy System for a Rural Community
}

\author{
Wemogar Elijah Borweh ${ }^{1}$, Emmanuel Asuming Frimpong ${ }^{2 *}$ and Lena Dzifa Mensah ${ }^{3}$ \\ ${ }^{1}$ Department of Electrical and Electronic Engineering, University of Liberia, Liberia \\ ${ }^{2}$ Department of Electrical and Electronic Engineering, \\ Kwame Nkrumah University of Science and Technology, Ghana \\ ${ }^{3}$ Department of Mechanical Engineering, \\ Kwame Nkrumah University of Science and Technology, Ghana \\ *Corresponding author, e-mail: eafrimpong.soe@knust.edu.gh
}

\begin{abstract}
This paper presents an optimized off-grid PV-diesel generator-battery hybrid energy system for application in an un-electrified rural community and further outlines a procedure for designing such an economical and technically feasible hybrid system. The hybrid optimization model for multiple energy resources (HOMER) software was utilized for simulation and analysis. The criteria of minimum net present cost of system, low $\mathrm{CO}_{2}$ emissions and zero electric load rejection was applied while considering technical issues of PV array, inverter coordination and PV capacity penetration level. For the case study system used, the obtained optimized hybrid energy system configuration is as follows: $68 \mathrm{~kW}$ PV plant; $40 \mathrm{~kW}$ Diesel plant; $45.4 \mathrm{~kW}$ Inverter; and $80 \mathrm{kWh}$ battery unit. The proposed hybrid energy system is capable of producing $157685 \mathrm{kWh}$ of electricity annually at a levelized cost of energy of $0.55 \$ / \mathrm{kWh}$ while emitting 51,000 kg of $\mathrm{CO}_{2}$ yearly. To avoid self-shading of the PV array, an appropriate inter-row distance was determined. The total quantity of PV modules and the electrical configuration of the PV array is presented.
\end{abstract}

\section{Keywords : Hybrid energy system, Net present cost, Optimal sizing and Photovoltaic}

\section{Introduction}

Electric energy remains the major driver for sustainable development. However, its associated adverse environmental impact and inaccessibility also continue to attract global attention [1]. For example, it is estimated that about $17 \%$ of the global population does not have access to electricity. Also, more than $80 \%$ of the this percentage that do not have electricity, reside in rural communities of developing Asia and Sub-Saharan Africa $[1,2]$.

There has been global implementation of energy-related policies and advanced technologies aimed at improving energy access, reducing greenhouse gas emissions and improving the well-being of people. These initiatives have resulted in improved energy access particularly in rural communities [1].

Research and implementation results have shown that the utilization of off-grid renewable energy-based systems, especially systems with distinct multiple energy sources (hybrid systems), are suitable for meeting the electricity needs of rural communities without electricity access. Moreover, the cost-effectiveness, minimization of greenhouse gas emissions, reduction in system losses and reliable electricity supply are among the many financial, environmental and technical benefits offered by well-engineered hybrid renewable energy systems [3].

However, these renewable energy systems are also faced with challenges including the varying nature of the energy sources, multiplicity of energy conversion technologies and high price of components. The issues of relatively high cost and poor performance of these systems, which are mostly associated with inappropriate design, continue to drive the quest for optimizing the design of renewable energy systems[4]. To achieve the optimization of renewable energy systems, several approaches including mathematical techniques and computerized algorithms are continuously being developed [57]. 
This paper adds to knowledge in the optimal design of off-grid energy systems. It presents an effective and efficient procedure for designing optimum off-grid PV-diesel generator-battery hybrid energy system for an un-electrified rural community. The study utilised the HOMER software tool [8]. The procedure applied to design the optimal hybrid energy system involved the estimation of electric energy demand, assessment of temperature and solar radiation at the study site, selection of components, determination of appropriate input parameters, and the determination of electrical configuration and optimum inter-row distance of PV array. These are discussed in the sections that follow.

\section{Selection, Sizing and Cost Estimation of Components}

Photovoltaic was the only renewable energy source considered in the study due to the fact that other renewable energy sources are not viable in the case study community. A diesel generator and an electric storage system (battery bank) were also utilized to increase the reliability of the system. The system components modeled were PV generator, diesel generator, converter and battery. The range of options for each component, which are required inputs of the decision variables were determined as explained in the sub-sections that follow. Also, the economic and technical inputs for modeling the proposed system were defined based on relevant information obtained from local companies in the solar industry of Ghana and from $[9,10]$.

\subsection{Photovoltaic generator}

The range of options of PV capacity is derived from (1) $[5,6]$.

$$
Y_{p v-\text { array }}=\frac{E_{A C-\text { daily }}}{f_{d^{*} \eta_{b} * \eta_{i n v} * S_{h}}}
$$

where, $E_{A C-\text { daily }}$ is the AC mean daily energy consumption of the community in $\mathrm{kWh} /$ day; $f_{d}$ is the derating; $\eta_{b}$ is the battery round trip efficiency; $\eta_{i n v}$ is the efficiency of the inverter; $S_{h}$ is the average peak sunshine hour which is defined as the ratio of the mean daily solar irradiation over the standardized global solar irradiance.

\subsection{Converter}

The bidirectional electric converter is a device designed to transform electric power from direct current (DC) to alternating current (AC) and vice-versa. Equation 2 along with assumptions on $\mathrm{PV}$ and inverter coordination was used to determine the range of options for the capacity of the converter $[5,6]$.

$$
R_{S}=\frac{P_{P V_{-} D C}}{P_{I N V_{-} A C}}
$$

where, $R_{S}$ is the sizing ratio; $P_{I N V_{-} A C}$ is the inverter rated output power (kW) and $P_{P V_{-} D C}$ is the PV array rated output power $(\mathrm{kW})$.

\subsection{Battery}

The range of options for the number of strings of battery is defined by $(3)[5,6]$.

$$
N_{(\text {string-bat })}=\frac{E_{(\text {total-bat })}}{E_{(\text {per-bat })}}
$$

where, $N_{(\text {string-bat })}$ is the maximum number of strings of the battery to be considered, $E_{(\text {total-bat })}$ is the total amount of energy the battery bank is capable of storing and $E_{(p e r-b a t)}$ is the amount of energy each battery is capable of storing.

Taking into account temperature effects and total electrical energy demand of the study site, the total energy of the battery bank was estimated as,

$$
E_{(\text {total-bat })}=\frac{E_{\text {daily } * T_{f} * D A * D M}}{\eta_{\text {bat }} * \eta_{\text {inv }} * D O D}
$$

where, $E_{\text {daily }}$ is the daily electrical energy demand of the study site; $T_{f}$ is the temperature correction factor; $D A$ is the day of autonomy, $D M$ is the design margin; $D O D$ is the depth to which the battery is discharged; $\eta_{b a t}$ is the round trip efficiency of the battery; $\eta_{i n v}$ is the inverter's efficiency.

The energy for one of the batteries is determined as,

$$
E_{(p e r-b a t)}=V_{(p e r-b a t)} * C_{(p e r-b a t)}
$$

where, $V_{(p e r-b a t)}$ is the nominal voltage for each battery in volts and $C_{(\text {per-bat })}$ is the nominal capacity for each battery in Ampere-hour.

\subsection{PV array arrangement}

The electrical arrangement of the PV array is determined by applying data for the selected PV 
module, charge controller and the selected optimized PV capacity to (6) [11].

$$
N_{\min -\bmod / \mathrm{s}} \leq N_{\bmod / \mathrm{s}} \leq N_{\max -\bmod / \mathrm{s}}
$$

where, $N_{\min -\bmod / \mathrm{s}}$ is the minimum number of PV modules per string that can maintain the operation of the charge controller, $N_{\bmod / \mathrm{s}}$ is the desired number of PV modules per string that is required to deliver optimum electrical power without stopping the required electrical function of the charge controller, $N_{\max -\bmod / s}$ is the maximum number of PV modules per string for which the maximum string voltage is less than the voltage of the maximum charge controller.

The maximum and minimum numbers of modules per string were determined using (7) while considering the influence of temperature on the PV system.

$$
N_{\min -\bmod / s} \geq \frac{V_{\text {min-input-cc }}}{V_{\text {min-mod }}}
$$

where, $V_{\min -\bmod / \mathrm{s}}$ is the minimum number of PV modules per string, $V_{\text {min-input-cc }}$ is the minimum input voltage of the charge controller and $V_{\text {min-mod }}$ is the minimum voltage of the PV module.

The maximum number of PV modules per string is also defined as,

$$
N_{\text {max }-\bmod / s} \leq \frac{V_{\text {max-input }-c c}}{V_{\text {max }-\bmod }}
$$

where, $V_{\text {max-input-cc }}$ is the maximum input voltage of the charge controller and $V_{\text {max-mod }}$ is the maximum voltage of the PV module.

The number of strings per module is also defined as:

$$
N_{S} \leq \frac{I_{\max -i c c}}{f_{S} * I_{s c-m o d}}
$$

where, $N_{S}$ is the number of strings of PV module, $I_{\max -i c c}$ is the maximum input current of the charge controller, $I_{s c-\bmod }$ is the short circuit current of the module and $f_{s}$ is safety factor.

\subsection{PV array inter-row distance determination}

The optimum inter-row distance of the PV array is determined as,

$$
d>l *\left[\frac{\sin \left(\theta_{t}\right) \cos \left(\gamma_{s}-\gamma\right)}{\sin \left(\alpha_{s}\right)}+\cos \left(\theta_{t}\right)\right]
$$

where, $d$ is the optimum distance that should exist between each row and $l$ is length of the row of modules. Equation (10) was developed by combining (11) and (12) [12, 13].

$$
\alpha_{s a}=\tan ^{-1}\left(\frac{u * \sin \left(\theta_{t}\right)}{1-u * \cos \left(\theta_{t}\right)}\right)
$$

where $\alpha_{s a}$ is the shading angle; $\theta_{t}$ is the angle at which each row is tilted relative to the horizontal and $u$ is the ground utilization factor. This factor is determined from dividing the length of the row of modules by the distance between each row.

$$
\alpha_{p}=\tan ^{-1}\left(\frac{\sin \left(\alpha_{s}\right)}{\cos \left(\gamma_{s}-\gamma\right)}\right)
$$

where $\alpha_{p}$ is the profile angle, $\alpha_{s o l}$ is the solar altitude angle; $\gamma$ is the azimuth angle of the reference surface which in this study is the orientation of the PV array which is south facing and $\gamma_{s}$ is the solar azimuth angle.

\subsection{Other inputs}

The economic, emissions and constraint input values used in the simulation, optimization and sensitivity analysis processes were obtained from current economic statistics of Ghana and recommendations from [8].

\section{Proposed Design Procedure}

The proposed procedure for designing an optimal PV-Diesel hybrid energy system for an unelectrified community is outlined as follow;

i. Estimate the electric energy demand. Here; one is required to determine the energy needs of the community considering future growth in demand. An already electrified community with similar characteristics can be a useful aid in the load estimation.

ii. Obtain temperature and solar radiation data for the community.

iii. Determine system components (i.e. PV, Battery, etc.) to be used (based on obtained data in step 2).

iv. Obtain input parameters for the determined components (in line with (i)-(iv)).

v. Obtain economic, emissions and constraint input values. (a) Typical economic input values are: discount rate, expected inflation rate, system fixed capital cost, system fixed 
operation and maintenance cost, capacity shortage penalty, fuel cost and cost of components. (b) Typical emissions input values consist of emission factors (gram/liter of diesel fuel) for carbon-monoxide, carbondioxide, unburned hydrocarbon, particulate matter, proportion of fuel sulfur converted to particulate matter and nitrogen oxides. (c) Typical constraint input values are: maximum annual capacity shortage, minimum renewable fraction, operating reserve as percentage of peak load and operating reserve as percentage of solar power output.

vi. Use appropriate software to determine the optimal system configuration.

vii. Determine the optimal PV configuration using (6)-(12).

\section{Case Study Community and Load Estimation}

Groso, a non-electrified rural community in Ghana, was used as the study site for the work. The community is located in the Amansie-West district of the Ashanti Region of Ghana. It has about 84 households with a population of 500 . Presently, the households of Groso individually rely on either kerosene, gasoline and diesel fuels to meet their energy needs. The distance between the nearest feeding point of the national electric grid and the Groso is about $20 \mathrm{~km}$.

Considering the fact that the study community does not have electricity, load estimation was done using Apenimandi, a nearby electrified community which has similar population, and social and economic activities. The present average daily energy required using Apenimandi as the reference was estimated to be $300 \mathrm{kWh}$ (see appendix for details). The estimated present peak load was $19 \mathrm{~kW}$. However, to account for future load growth, the hybrid system was designed to meet a daily peak demand of $29.4 \mathrm{~kW}$. Solar radiation and temperature data were obtained from NASA [14].

\section{Software used}

The hybrid optimization of multiple electric renewables (HOMER) software was used for modelling and simulation [8]. HOMER simplifies the task of evaluating and designing grid-connected and off-grid power systems. It uses inputs describing technology options, component costs and resource availability to generate results of feasible configurations sorted by net present cost. It simulates the operation of a system by applying energy balance calculations in each time step.

\section{Results and Analysis}

Table 1 shows the configuration and general performance of the optimized hybrid energy system. The following requirements had to be met in the optimization process: minimum $\mathrm{CO}_{2}$ emissions, low net present cost and zero electric load rejection. It is important to note that the actual output of the plants, particularly the PV, is highly dependent on PV efficiency as well as atmospheric and operating conditions. The performance of the proposed hybrid energy system is discussed in two core areas namely, technical performance and economic performance.

Table 1. Configuration and performance of optimized systems

\begin{tabular}{|l|l|l|}
\hline No. & \multicolumn{1}{|c|}{ Quantity/Parameter } & Value \\
\hline 1 & PV $(\mathrm{kW})$ & 68 \\
\hline 2 & Diesel $(\mathrm{kW})$ & 40 \\
\hline 3 & Battery $(\mathrm{kAh})$ & 80 \\
\hline 4 & Converter $(\mathrm{kW})$ & 45.4 \\
\hline 5 & Cost of Energy $(\$)$ & 0.554 \\
\hline 6 & Net present cost $(\$)$ & 933571 \\
\hline 7 & Operating cost $(\$)$ & 39251 \\
\hline 8 & Initial capital $(\$)$ & 329888 \\
\hline 9 & Renewable fraction $(\%)$ & 38 \\
\hline 10 & Total fuel $(\mathrm{L})$ & 19414 \\
\hline 11 & Electricity production $(\mathrm{kWh} / \mathrm{yr})$ & 157685 \\
\hline 12 & Electricity consumption $(\mathrm{kWh} / \mathrm{yr})$ & 109500 \\
\hline 13 & Excess electricity (kWh/yr) & 48185 \\
\hline 14 & CO 2 (kg/yr) & 51123.1 \\
\hline 15 & Diesel operation (hours) & 2471 \\
\hline 16 & Battery autonomy (hours) & 16.2 \\
\hline
\end{tabular}

\subsection{Technical performance}

Figure 1 shows the contribution of each plant to the maximum demand for each month. It is observed from Figure 1 that the PV and diesel generators' contribution to the peak demand varies moderately over the year. The PV 
generator supplies a greater share of the monthly maximum demand. The only exception is in the month of August due to less availability of solar radiation.

Figure 2 shows the contribution of the plants to the annual electric energy production. The PV generator accounted for almost $57 \%$ $(89720 \mathrm{kWh})$ of the annual electric energy production of $157,685 \mathrm{kWh}$. This high share of renewable energy in the generation mix of the hybrid system indicates relatively less operational hours of the diesel generator thereby reducing diesel fuel consumption as well as $\mathrm{CO}_{2}$ emissions.

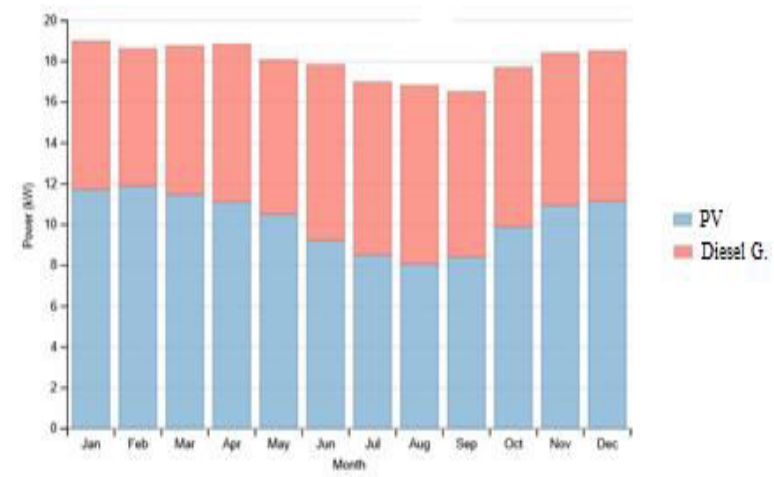

Figure 1. Plant contribution to maximum monthly demand

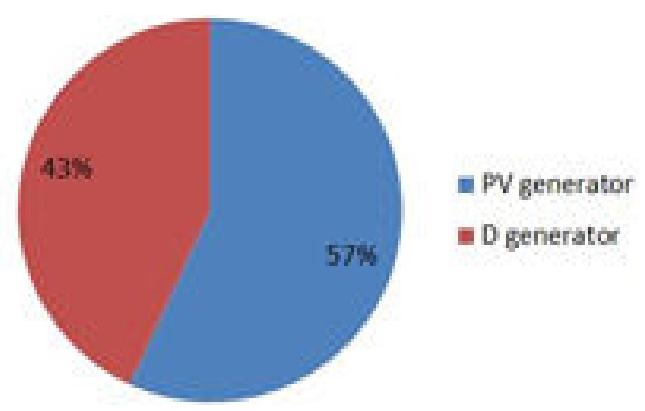

Figure 2. Contribution of generators to annual energy production

\subsection{Economic performance}

The economic performance of the selected optimized hybrid energy system takes into consideration the cost of the entire system in terms of initial capital, operation and maintenance, fuel and salvage costs.

Figure 3 shows the contribution of each component to the capital cost. It is noted that the PV contributes the highest percentage $(62 \%)$ to the capital cost with the least contributor being the diesel generator.

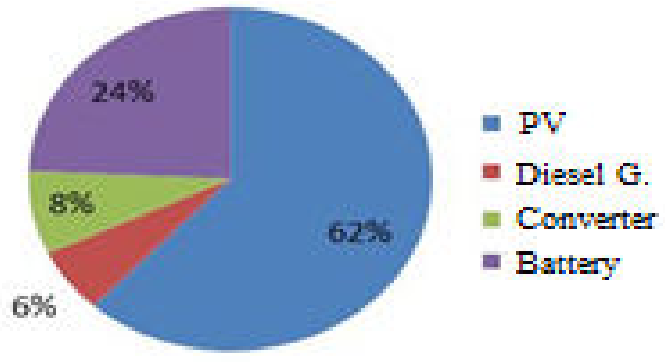

Figure 3. Components' share of initial capital cost

Figure 4 shows the contribution of each system component to the net present cost (NPC). Here, the diesel generator contributes the highest percentage $(49 \%)$ while the converter is the least contributor $(5 \%)$.

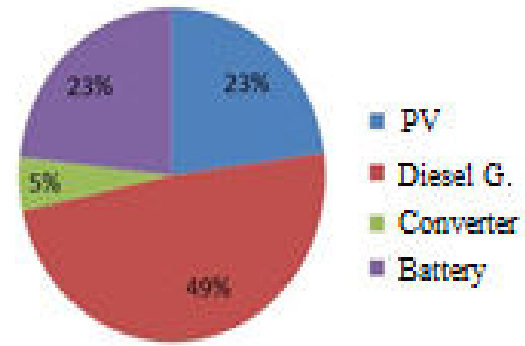

Figure 4: Components' contribution to net present cost

\subsection{Arrangement of PV modules}

Based on the determined PV capacity, temperature of the study site and technical characteristics of the selected charge controller and inverter, the total number of PV modules was determined to be 212. The electrical arrangement is as follows: four set of 4 modules per string with 11 strings and one set of 4 modules per string with 9 strings. Furthermore, from data analysis done, the optimum inter-row distance for the PV array is determined to be greater than 4.22 meters.

\section{Conclusion}

An optimized off-grid PV-Diesel-Battery hybrid energy system for a rural community has been presented. The levelized cost of energy of the system is comparable to other existing offgrid renewable hybrid energy systems. The procedure presented in this study can be applied in designing economical and technically feasible PV-diesel generator-battery hybrid energy systems for other rural communities with favourable solar energy resources. 


\section{Acknowledgement}

The authors are grateful to the Excellence in Higher Education for Liberian Development (EHELD) Program and United States Agency for International Development (USAID) for providing financial support for the study.

\section{References}

[1] World Energy Outlook - International Energy Agency (2011). Available at: https://www.iea.org/publications/freepub lications/publication/weo2011_web.pdf

[2] Global Status Report on renewables (2016). Available at: www.ren21.net/wpcontent/uploads/2016/05/GSR_2016 Ful 1 Report lowres.pdf

[3] A. Afzal, H. Kumar and V.K. Sharma, "Hybrid renewable energy systems for energy security using optimization technique", in International Conference \& Utility Exhibition on Power and Energy Systems: Issues and Prospects for Asia (ICUE), 2011

[4] Rural Electrification with PV Hybrid Systems - Overview and Recommendations for Further Deployment, an IEA-PVPS report (2013). Available: http://www.ieapvps.org/fileadmin/dam/public/report/nat ional/Rural_Electrification_with_PV_Hy brid_systems_-_T9_-_11072013_Updated Feb $2014 . \overline{p d f}$

[5] M. S. Adaramola, M. Agelin-Chaab, M. and S. S. Paul, "Analysis of hybrid energy systems for application in southern Ghana", in Energy Conversion and Management, vol. 88, pp. 284-295, 2014.

[6] M. S. Adaramola, S. S. Paul and O. Oyewola, "Assessment of decentralized hybrid PV solar-diesel power system for applications in Northern part of Nigeria", Energy for Sustainable Development, vol. 19, pp. 72-82, 2014.

[7] E. S. Hrayshat, "Off-grid hybrid winddiesel power plant for application in remote Jordanian settlements", Clean Technologies and Environmental Policy, vol. 11, no. (4), pp.425-436, 2009.

[8] HOMER ® Pro Version 3 . 7 User Manual (2016). Available at: https://www.homerenergy.com/pdf/HO

MERHelpManual.pdf

[9] Renewable energy market analysis: The GCC Region (2016). Available at: https://www.irena.org//media/Files/IRENA/Agency/Publication 2016/IRENA_Market_GCC_2016.pdf

[10] Solar PV in Africa: Costs and Markets (2016). Available at:

http://www.irena.org/publications/2016/

Sep/Solar-PV-in-Africa-Costs-and-

Markets

[11] Planning of a PV Generator - Planning Guidelines - SMA (2013). Available at: http://files.sma.de/dl/1354/DC-PL-en11.pdf

[12] V. Quaschning,Understanding Renewable Energy Systems, 2016.

[13] J.A. Duffie and W. A. Beckman, Solar Engineering of Thermal Processes, Fourth Edition, 2013.

[14] NASA atmospheric science data center (2016). Available at:

www.https://eosweb.larc.nasa.gov/cgibin/sse/grid.cgi. 